\title{
Çelik payandalarla güçlendirilmiş Tokat Deveci Hanı'nın sismik analizi
}

\author{
Murat ÇAVUŞ ${ }^{1, *}$, Şahin SÖZEN ${ }^{1}$ \\ ${ }^{I}$ Gaziosmanpaşa Üniversitesi Müh.-ve Doğa Bil. Fak. İnşaat Müh. Böl. Taşllçiftlik kampüsü, Tokat.
}

Geliş Tarihi (Recived Date): 02.10.2017

Kabul Tarihi (Accepted Date): 09.08.2018

\section{Özet}

Çelik payandalarla tarihi yapıların desteklenmesi ve güçlendirilmesi işlemi ülkemizde birçok yapıda kullanılmaktadır. Malzeme özellikleri ve mekanik davranış bakımından birbirinden farklı iki yapının etkileşimi oldukça önemli ve tartışmalı bir konudur. Bu çalışmada restorasyonu daha önce tamamlanmış ve bir kısmı çelik payandalarla desteklenmiş olan Tokat Deveci Hanı'ndaki uygulamanın mevcut yapı ile etkileşimi incelenmiştir. Çalışmada mevcut tarihi yapının belli bir bölümünden alınacak prototip model üzerinde yapının bulunduğu bölgenin zemin ve deprem durumu göz önüne alınarak oluşturulan spektrum eğrileri dikkate alınarak yapı sonlu elemanlar metoduyla Sap 2000 programında modellenmiş ve analizleri yapılmıştır. Analiz sonuçlarına göre muhtemel depremlere karşı tarihi yapıyı güçlendirmek amacıyla inşa edilen payandaların, yapı elemanlarında oluşan gerilmeler ve yapı periyodunu azaltma noktasında çok küiçük bir etkisinin olduğu tespit edilmiştir.

Anahtar kelimeler: Sismik analiz, tarihi yapı, çelik payanda, güçlendirme, restorasyon.

\section{Seismic analysis of Tokat Deveci Inn reinforced with steel buttresses}

\begin{abstract}
The supporting and retrofitting of the historical buildings with steel buttresses is common in many buildings in our country. The interaction of the two different structures in terms of material properties and mechanical behavior is extremely important and controversial. In this study, the interaction between existing historical structure, Tokat Deveci Inn which had been restored and some parts of which were
\end{abstract}

\footnotetext{
* Murat ÇAVUŞ, murat.cavus @gop.edu.tr, https://orcid.org/0000-0002-9480-4418

Şahin SÖZEN, sahin.sozen@gop.edu.tr, https://orcid.org/0000-0002-2480-9723
} 
supported by buttresses, and steel buttresses was studied. To this end, the prototype model which is the certain part of the existing building was modeled using structural analysis program SAP2000. The spectral curve which was generated taking into account the ground and earthquake condition of the region where the structure was constructed, was used in the finite element model. Analyzes shows that, buttresses built to reinforce the historical structure against the possible earthquakes has little effects on decreasing the stresses occurred on structural members and the period of the historical structure.

Keywords: Seismic analysis, historical masonry structure, steel buttress, strengthening, restoration.

\section{Giriş}

Tarihi yapıların bir bölümü, inşasında kullanılan malzemelerin mekanik özelliklerine, yapım tekniğine ve bulundukları yere bağlı olarak yüzlerce yıl ayakta kalarak günümüze kadar ulaşabilmişlerdir. Günümüze ulaşan bu yapıların birçoğu, oluşan hasarlar nedeniyle zaman içinde çeşitli müdahalelerle onarılmışlardır. Tarihi yapılarda ortaya çıkan hasarların büyük bölümünü depremler, yangınlar ve savaşlar oluşturmaktadır. Özellikle Türkiye' de, tarihi yapıların birçoğunda ortaya çıkan hasarlarda (zamana bağlı malzeme dayanım kayıplarının yanında) depremler önemli bir etki olarak kendini göstermektedir [1,2]. Bu yapılar, üzerinde bulundukları topraklarda yaşamış olan topluluklara ait sosyokültürel yaşam, yapı mimarisi, yapım tekniği ve inşada kullanılan malzeme özelliklerini yansıtması bakımından önemli birer belge niteliğindedirler. $\mathrm{Bu}$ yüzden, hasar gören bu yapıların ve üzerinde barındırdıkları verilerin gelecek kuşaklara aktarılabilmesi için onarılarak yeniden kullanıma açılması gerekmektedir. Ancak, çok yoğun tarihi yapı birikimine sahip olan ülkemizde onarım ve güçlendirme faaliyetleri oldukça maliyetli olduğundan ve ayrıca hassas teknik bilgi ve tecrübe gerektirdiğinden çoğu zaman istenilen şekilde devam edememektedir.

Tarihi yapıların onarımında esas olan, üzerinde barındırdığı tarihsel dönemlere ait verilerin kaybolmadan onarılmasıdır. Bu yüzden, tarihi yapıların onarımında genellikle yapının özgün malzemesiyle uyumlu malzemeler kullanılmaktadır. Ancak özgün malzemeye eşdeğer malzemenin elde edilemediği veya bazı yapısal sorunların aşılamadığı durumlarda, tarihi yapı onarımlarında çağdaş malzemelerin de kullanıldığı görülmektedir (Resim 1). Bu çalışmaların bir kısmında karbon fiber, takviyeli harçlar veya çeliğin kullanıldığı görülmektedir. Bu hususta dikkat edilmesi gereken temel nokta, hangi uygulama olursa olsun, yapının özgün malzeme özelliklerine zarar verilmeden uygulanmasıdır. Yapı çeliği, uygulama kolaylığı, yapıya en az zararla sökülüp takılabilmesi (montaj-demontaj), mimari forma uyum kabiliyeti, ince kesitlerle çalışılabilmesi gibi avantajlarının yanında özellikle yüksek elastisite modülüne sahip olması sebebiyle tarihi yapılarda kalıcı yada geçici destek malzemesi olarak kullanıldığı bilinmektedir. Karbon fiber genellikle duvar ve tonoz stabilitesi için kullanılırken [3], yapısal çelik daha çok eleman ya da tüm yapı desteklemelerinde kullanılmaktadır (Resim 1). 


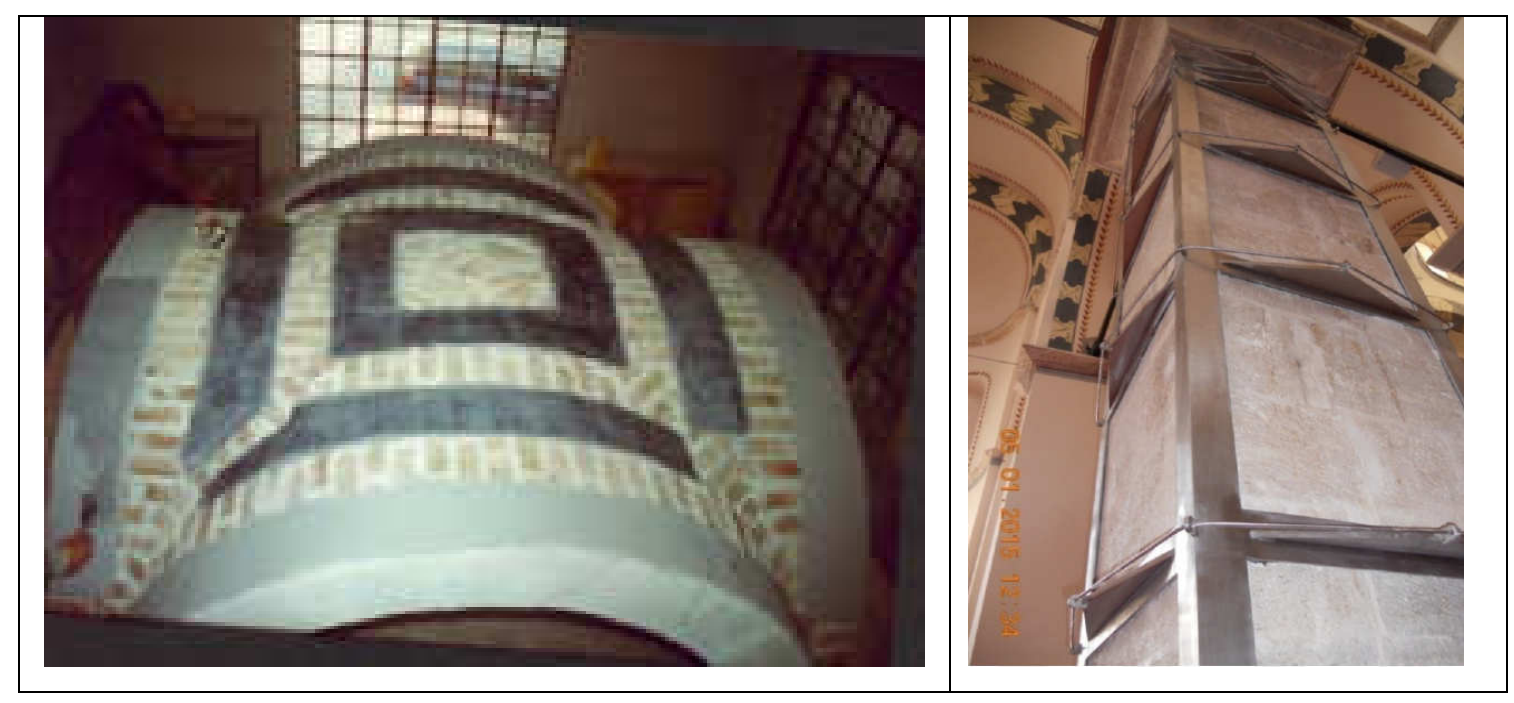

Resim 1. Tarihi yapıların karbon fiber ve çelik ile güçlendirilmesi.

Ülkemizde yapılan bazı uygulamalarda çeliğin, yapı dışında ve daha çok payanda elemanı olarak kullanıldığını görülmektedir. Ancak iki farklı mekanik davranış ve malzeme özelliklerine sahip yapının birlikte çalışmasının nasıl olabileceği tartışmalı bir konudur. Tarihi yapılar, betonarme ya da çelik yapılara kıyasla daha büyük kesitlerle ve daha az katlı teşkil edildiklerinden, çok ağır yapılar olarak yatay yükler altında daha kısa periyotlarla salınmaktadırlar [4]. Çelik yapılar ise yüksek mukavemete sahip olmaları gereği ince kesitlerle çalışabilme imkanı sağlaması nedeniyle yüksek salınım periyot değerlerine ulaşabilmektedir. Davranış karakteristikleri açısından tamamen farklı bu iki yapının bir araya getirileceği uygulamalarda, titiz bir projelendirme çalışması ile yapıların çok iyi analiz edilmesi ve birleşim detaylarının sağlıklı olarak çözümlenmesi son derece önemlidir.

$\mathrm{Bu}$ çalışmada, bir kısmında çelik payandalar kullanılarak restorasyonu tamamlanmış tarihi bir yapı için, çelik destek yapısından beklenen faydanın gerçekleşip gerçekleşmediği araştırılmıştır. Bu amaçla yapının payandalı ve payandasız modelleri bilgisayar ortaminda sonlu elemanlar yöntemiyle modellenerek Türk deprem yönetmeliğine göre analizleri yapılmıştır. Analiz sonuçları baz alınarak yapının taşıyıcı elamanları olan duvar ve tonozlarında meydana gelen gerilmeler, gerilme yığılmaları ve deformasyonlar karşılaştırmalı olarak değerlendirilmiştir.

\section{Tokat Deveci Hanı}

Tokat il merkezinde yer alan Deveci Hanı, yapılış tarihi ve kimin tarafından yaptırıldığı tam olarak bilinmemekle birlikte, XV-XVI yüzyılda inşa edildiği tahmin edilmektedir. Hanın adı Eski Eserler ve Müzeler Genel Müdürlüğü (EEMGM) Doğal ve Kültürel Varlıkları Koruma envanterinde Deveci Hanı olarak geçmektedir [5]. Yapı doğu-batı yönünde ortalama $60 \mathrm{~m}$, kuzey güney yönünde $35 \mathrm{~m}$ boyutlarındadır. Yapıda, açıklık geçmede genel olarak tonozlar kullanılmıştır. Sadece giriş mekânının üstü kubbeyle örtülmüştür. Yapı duvar kalınlıkları, bölmelerde 0,80-0,90 m arasında, zemin katta beden duvarlarında 1,35-1,40 m, avluya bakan duvarlar ise ortalama $1,30 \mathrm{~m}$ civarındadır. Üst katta avluya bakan duvarlar 1,00-1,10 m, kuzeye bakan duvar ise 1,20 m civarındadır. (Resim 2 ) 


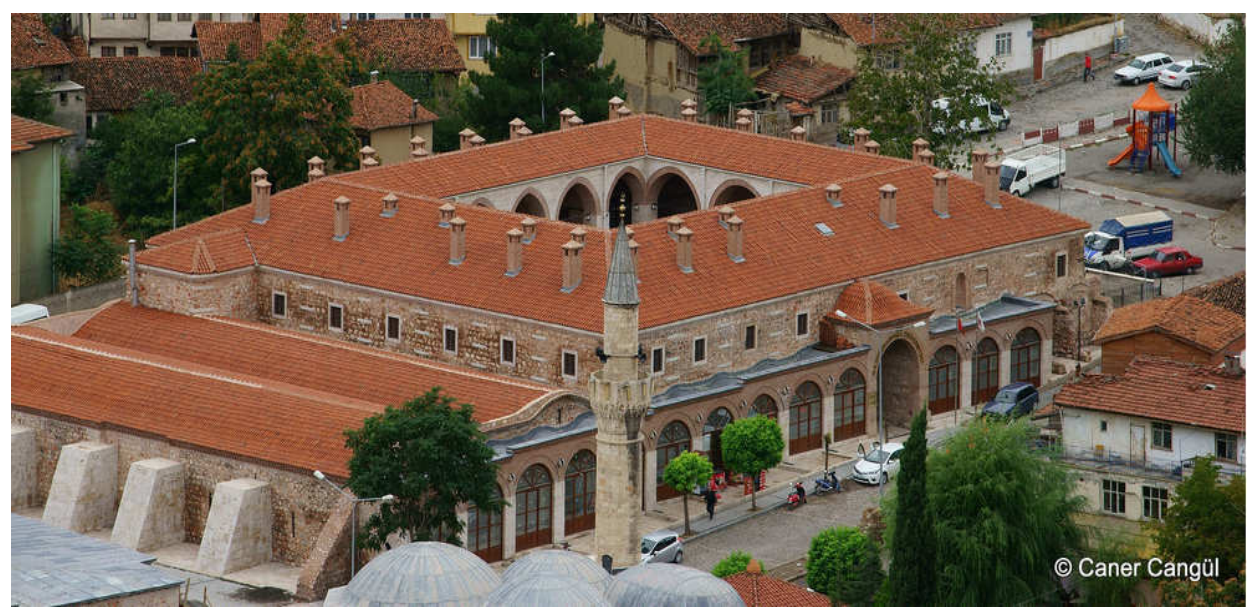

Resim 2. Tokat deveci hanı genel görünümü [6].

Yapı 2008-2013 yılları arasında restore edilmiştir. Yapının genel onarımlarında, özgün malzemeye eşdeğer malzeme kullanılmaya çalıșılmış, bunun yanında dış duvar desteklemesi ve güçlendirme için yapının güney-batı dış duvarında çelik payandalar kullanılmıştır (Resim 3). Payanda konstrüksiyonu, üçgen formlu kafes olarak S235JR kalitesinde çelik malzemeyle HEA300 hadde profillerinden oluşturulmuştur. Profiller düğüm noktalarına kaynaklı olarak birleştirilmiştir. Projelendirmede payanda-tarihi yapı bağlantısını, dikmeler üzerine inşa edilmiş guse levhalarına serbest olarak oturtulmuş IPE profilinin sağlayacağ düşünülmüştür.

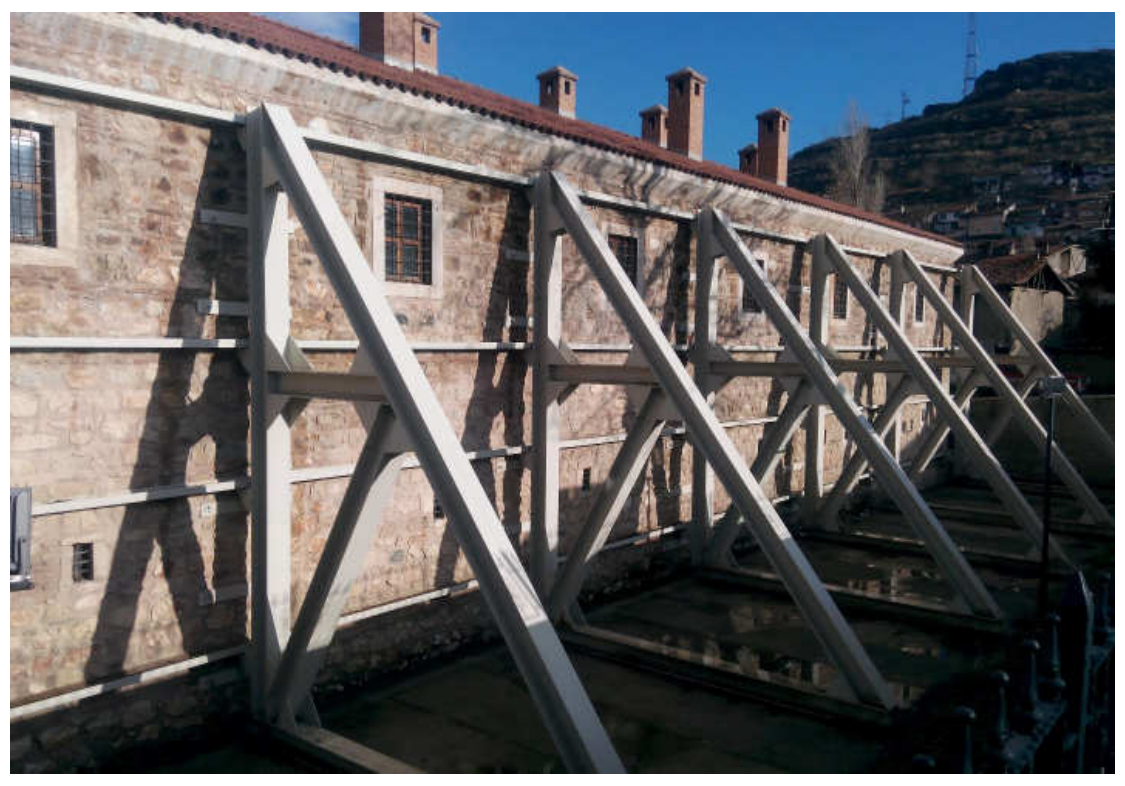

Resim 3. Yapıda uygulanan çelik payanda sistemi.

\section{Yapısal modelleme ve analiz parametreleri}

Tarihi binaların yapısal analizi günümüzün modern yapım tekniklerine göre üretilen yapıların analizlerinden farklıdır [7,8]. Modelleme aşamasında, eleman boyutlarının tam olarak belirlenememesi, birleşim detaylarının yeterince tanımlanamaması, malzemelerin 
gerçek mekanik özellikleri ve sınır gerilme değerlerinin elde edilememesi gibi belirsizlikler nedeniyle hesap sonuçlarının yorumlanmasında, benzer binaların yapısal davranışlarında gözlenen deneyimler ön plana çıkmaktadır [9-11].

Bu çalışmada yapılan modellemede, yapıda kullanılan malzemelerin (taş, tuğla ve harç bileşimleri) doğrusal elastik özelliklere sahip olduğu, yapıyı oluşturan elamanların iç kısımlarının malzeme özelliklerini belirlemek mümkün olmadığından, elemanların dış yüzeylerindeki malzeme özelliklerinin, kesitin her yerinde aynı olduğu kabul edilmiştir $[4,7,12]$. Yapı temeli, literatürdeki benzer çalışmalarda olduğu gibi tam ankastre olarak modellenmiştir [11,13]. Modellemede yapının restorasyon projelerine sadık kalınmıştır (Resim 1).

Yapının tamamıyla gerçekleștirilen ön analizlerde, gerilme yığılmalarının ve deformasyonların daha az rijit olduğu bilenen revak kısımlarında toplandığ görülmüştür. $\mathrm{Bu}$ durumun, çalışmanın odak noktası olan çelik payanda-yapı etkileşiminin gözlemlenmesini zorlaştırması nedeniyle, yapısal çözümlemelerde yalnızca çelik payandalarla güçlendirilmiş olan bölüm dikkate alınmıştır. Revak kısımları ve yapının kalan kısmı modele dâhil edilmemiştir. Analiz sonuçlarında çelik payanda-yapı etkileşiminin daha rahat izlenebilmesi için yapı, payandalı ve payandasız olarak modellenmiștir. Modellemede Sap 2000 yapısal analiz programı kullanılmıștır. Yapının duvar ve tonozlarında eleman alt ve üst gerilmelerinin ayrı ayrı görülebilmesi için bu elemanlar program kütüphanesinde bulunan shell-tick sonlu elemanı, payanda konstrüksiyonu frame elemanı kullanılarak modellenmiştir. [14].

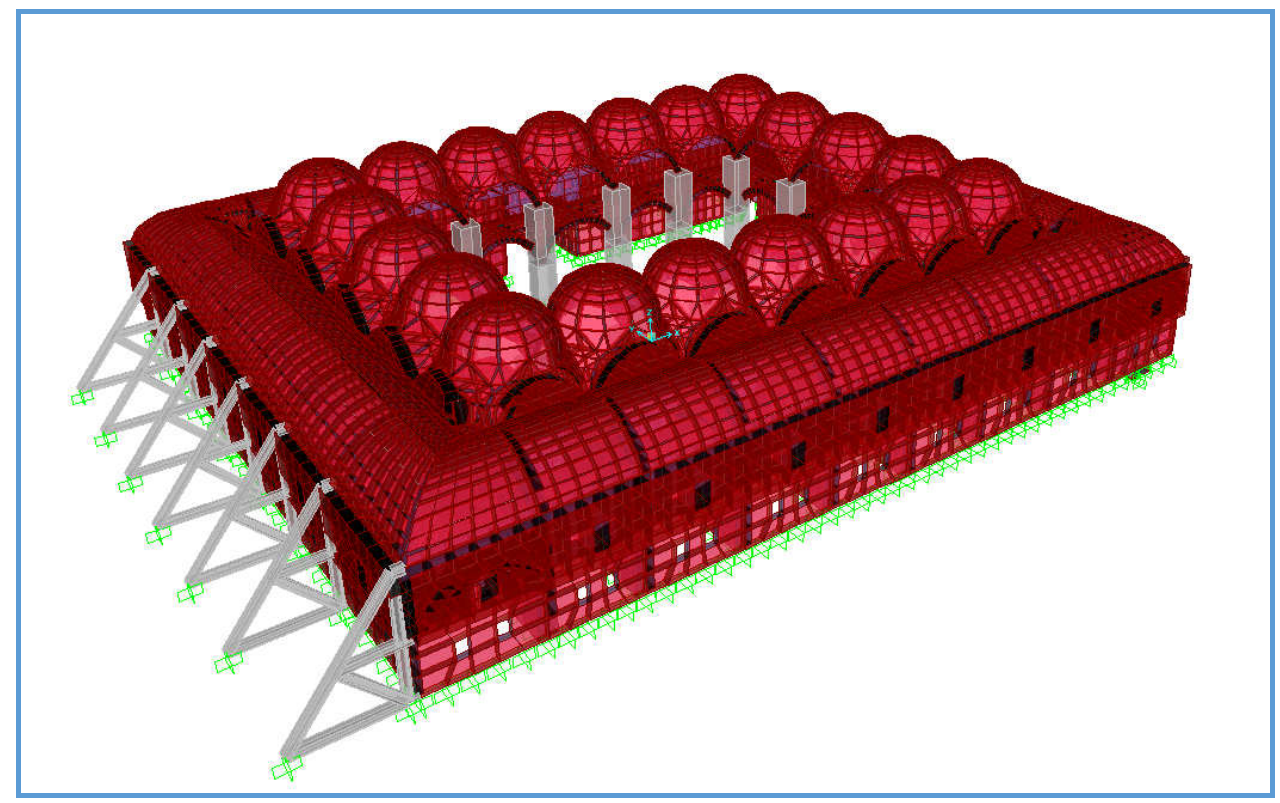

Şekil 1. Tüm yapının sonlu elemanlar modeli.

Hazırlanan matematiksel modellerde, payandasız durum için 2472 dügüm noktası ve 2779 shell elemanı kullanılmış, payandalı modelde ise 2536 düğüm noktası, 2779 shell elemanı ve 98 frame elemanı kullanılmıştır (Şekil 2). Her iki modelin statik ve dinamik analizi için, sabit yükler ve deprem spektrumu ile tanımlanan yer hareketinin yol açtığı zorlamaların göz önüne alındığı iki ayrı yükleme uygulanmıştır. 
Dinamik analizde, yapının bulunduğu yerin yerel zemin sınıfı ve deprem koşulları dikkate alınarak oluşturulan spektrum eğrisi kullanılmıştır [15]. Diğer parametreler Tablo 1'de verilmiştir.

Tablo 1. Analizde kullanılan parametreler.

\begin{tabular}{|l|l|}
\hline Deprem bölgesi & $1(\mathrm{Ao}=0,40)$ \\
\hline Zemin sınıfı & Z2 (Orta Sıkı kum, çakıl) \\
\hline Spektrum katsayısı & 2.5 \\
\hline Bina önem katsayısı & 1 \\
\hline Taşıyıcı sistem davranış katsayısı (Ra) & 2.5 \\
\hline
\end{tabular}

Yapılan güçlendirme/destek uygulamasında tarihi yapı ile çelik destek yapısı arasında ankraj kullanılmamıştır. Düşünülen destekleme herhangi bir ankrajın bulunmayışı sebebiyle tek yönlü olarak çalışabilecektir. Bu sebeple yapılan çalıșma sismik bir güçlendirme anlamı taşımamakta sadece tek yönlü destek anlamı taşımaktadır. Bu noktada çelik destek kafeslerinin yapının göreceli olarak daha rijit olan ve dış cephe duvarına dik iç bölme duvarları hizasına getirilmesi de ayrıca dikkate alınmalıdır. Yukarıda anılan sebeplerle çelik destek yapısı ile tarihi yapı arasındaki temas ilişkisi, yapısal modele tek yönlü bağlantı sağlayan fiktif elemanlarla yansitılmıştır. Söz konusu elemanlar çekme kuvveti aktarmazken tarihi yapıdan çelik destek yapısı üzerine gelebilecek basınç kuvvetlerini aktarabilmektedirler. Modellemede yerinde yapılmış uygulamaya sadık kalınmıştır. Çelik payandaların yapıyla etkileşiminin detaylı olarak gözlemlenebilmesi için, iki farklı yük kombinasyonu iki asal doğrultu için ayrı ayrı tanımlanmıştır. Modal analizde payandasız model için ilk 60 mod, payandalı model için ilk 68 mod dikkate alınmıştır. Payandalı modelde ilk 7 modu payandaların davranışı belirlediğinden karşılaştırmanın sağlıklı olarak yapılabilmesi için payandalı modelde 8 . moddan sonraki veriler dikkate alınmıştır.

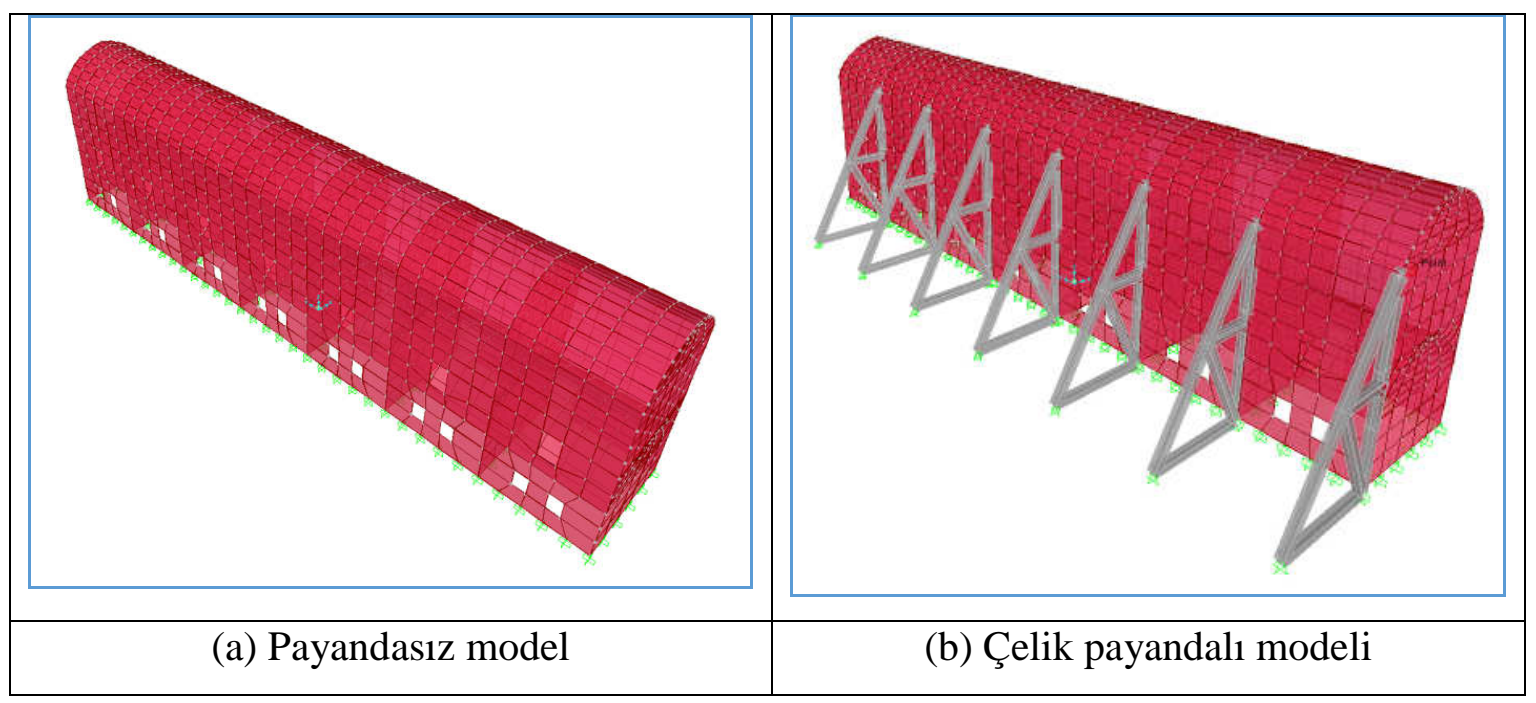

Şekil 2. Analizi yapılan yapının ilgili modelleri.

Tarihi yapıların analiz çalışmaları yapılırken ya literatürde kullanılan malzeme değerleri ya da ilgili yapıdan alınacak numuneler üzerinde yapılacak analizlerden elde edilen veriler kullanılmaktadır. Bu çalışmada gerekli yasal izinler alınamadığı için malzeme 
deneyleri yapılamamış ve duvar ve tonoz elemanları için literatürde yer alan taş- harç ve tuğla-harç için geçerli malzeme özellikleri dikkate alınmıştır. Tablo 2, [8,16,17].

Tablo 2. Yapıya ait sonlu elemanlar modelindeki malzeme özellikleri.

\begin{tabular}{|c|c|c|c|}
\hline Malzeme & $\begin{array}{c}\text { Elastisite modülü } \\
(\mathrm{MPa})\end{array}$ & $\begin{array}{c}\text { Özgül ağırlık } \\
\left(\mathrm{kN} / \mathrm{m}^{3}\right)\end{array}$ & $\begin{array}{c}\text { Poisson } \\
\text { Oranı }\end{array}$ \\
\hline Tuğla tonoz (harç ile birlikte) & 4500 & 18 & 0,15 \\
\hline Taş duvarlar (harç ile birlikte) & 4500 & 24 & 0,17 \\
\hline Çelik & 200000 & 78,5 & 0,3 \\
\hline
\end{tabular}

\section{Yapisal analiz}

Yapısal analiz, SAP2000 yapısal analiz programı yardımıyla, tanımlanan sabit yük ve deprem spektrumu yükleme durumlarına göre gerçekleştirilmiş, sonuçlar yük kombinasyonları ile birleştirilmiştir. Analiz sonuçlarının yorumlanmasında bütün dügüm noktaları ve taşıyıcı elemanlarda elde edilen ötelenme, kuvvet ve gerilmelerin tek tek incelenerek yorumlanması oldukça zor olduğundan, analiz sonuçlarının yorumu, SAP2000 programının ürettiği renk kodlu gerilme haritalarındaki en elverişsiz değerler dikkate alınarak yapılmıştır.

Literatürdeki çalışmalarda, yığma yapıların modal analiz sonuçlarına göre elde edilen periyotlarının küçük olduğu göz önüne alındığında, bu yapı için elde edilen değerlerin tutarlı olduğu görülmektedir. Analiz sonuçlarında payandasız model için ilk 3 moda karşılık, payandalı yapıda 8 ila 10. modlar arası dikkate alınmıştır (Şekil 3). Tablo 2 de verilen Modal analiz sonuçları incelendiğinde, çelik payandaların yapı periyodunun azalması yönünde çok az bir etkisinin olduğu görülmüştür. Yine aynı tabloda verilen $\mathrm{x}$ ve y yönü deprem etkileri altında kütle katılım oranları incelendiğinde de payandaların kayda değer bir katkısının olmadığı görülmektedir.

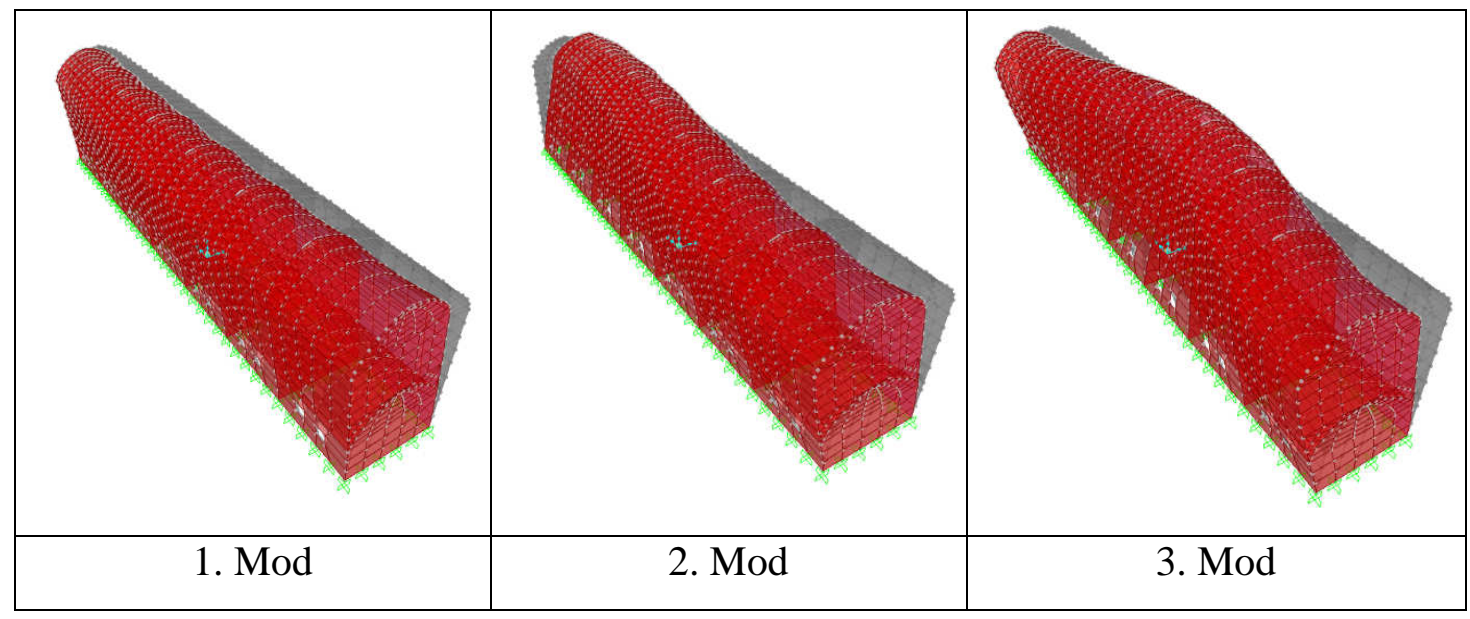

Şekil 3. Yapının payandalı ve payandasız modellerinin mod şekilleri. 


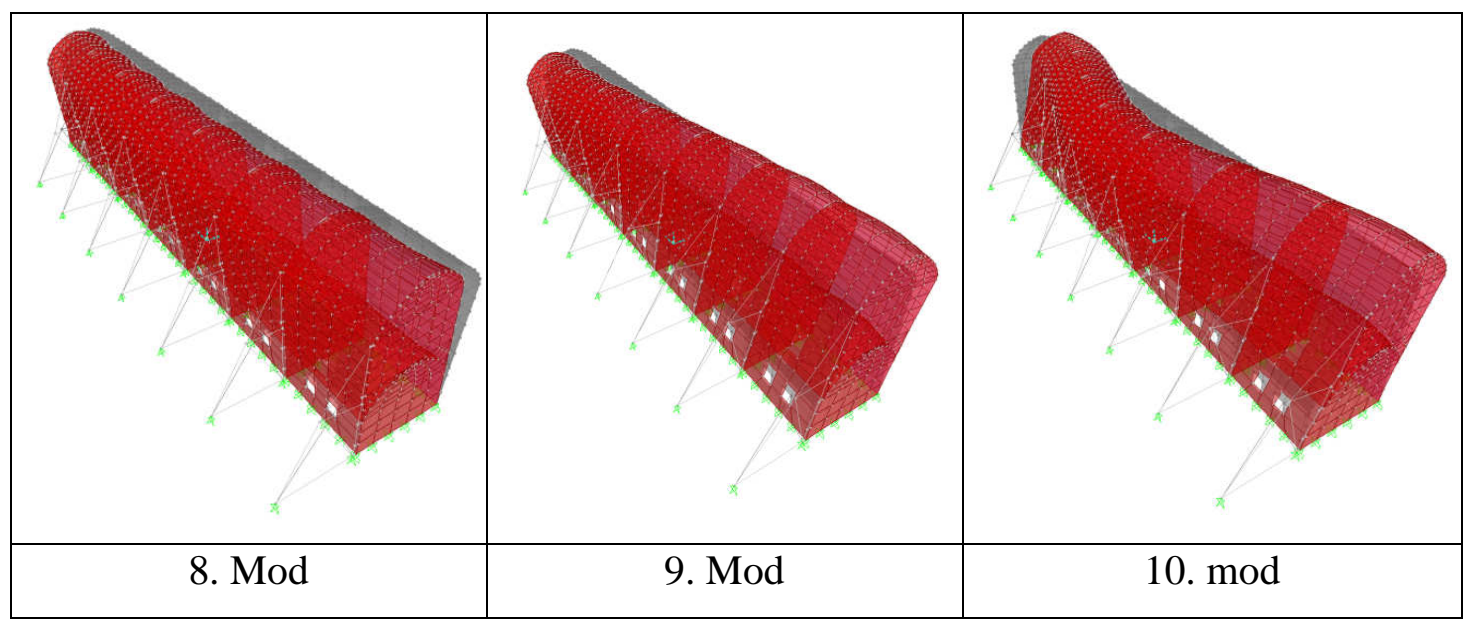

Şekil 3. (Devamı) Yapının payandalı ve payandasız modellerinin mod şekilleri.

Tablo 2. Modlara göre periyotlar ve kütle katılım oranları.

\begin{tabular}{|c|c|c|c|c|c|c|c|}
\hline \multirow{2}{*}{ Mod } & \multicolumn{2}{|c|}{$\begin{array}{c}\text { Periyot } \\
(\mathrm{s})\end{array}$} & $\begin{array}{c}\text { Fark } \\
\%\end{array}$ & \multicolumn{2}{c|}{$\begin{array}{c}\text { X Yönü Kütle Katılım } \\
\text { Oranı }\end{array}$} & $\begin{array}{c}\text { Y Yönü Kütle Katılım } \\
\text { Oranı }\end{array}$ \\
\cline { 2 - 8 } & Payandasız & Payandalı & & Payandasız & Payandalı & Payandasız & Payandalı \\
\hline $1 / 8$ & 0,07718 & 0,07249 & $-0,06$ & 0,72961 & 0,73455 & 0 & 0,00332 \\
\hline $2 / 9$ & 0,06910 & 0,06544 & $-0,05$ & 0,72977 & 0,7373 & 0 & 0,00353 \\
\hline $3 / 10$ & 0,05675 & 0,05481 & $-0,03$ & 0,73651 & 0,74432 & 0 & 0,00463 \\
\hline $4 / 11$ & 0,05041 & 0,05051 & $-0,00$ & 0,73651 & 0,74439 & 0,79514 & 0,79846 \\
\hline $5 / 12$ & 0,04609 & 0,04527 & $-0,02$ & 0,73651 & 0,74459 & 0,79565 & 0,79847 \\
\hline $60 / 70$ & 0,01864 & 0,01837 & $-0,00$ & 0,89639 & 0,89687 & 0,91208 & 0,91258 \\
\hline
\end{tabular}

Yapının payandasız ve payandalı modeli için toplam ağırlığı sırasıyla $21113 \mathrm{kN}$ ve $21272 \mathrm{kN}$ olarak hesaplanmıştır. Analizlerden elde edilen sonuçlar Tablo 3'te görülmektedir. Her iki modelde kısa kenar yönündeki deprem yük kombinasyonu sonucunda en büyük ötelenme payandasız ve payandalı model için tonoz tepesinde sırasıyla $1,7 \mathrm{~mm}$ ve $1,5 \mathrm{~mm}$, uzun kenar yönünde ise her iki model için yine tonoz tepesinde $0,65 \mathrm{~mm}$ olarak gerçekleşmiştir. Ötelenme değerlerinin oldukça küçük olduğu not edilmelidir. Her iki model için hesaplanan ve tablo 3 'te verilen taban kesme kuvvetleri incelendiğinde, payandalı modelde taban kesme kuvvetinin kayda değer bir değişikliğe uğramadığı görülmektedir.

Tablo 3. Taban kesme kuvvetleri ve eksenel kuvvetler.

\begin{tabular}{|l|l|l|r|r|r|r|}
\hline Yükleme tipi & \multicolumn{1}{|c|}{ Analiz tipi } & & \multicolumn{2}{|c|}{$\begin{array}{c}\text { X yönünde meydana } \\
\text { gelen taban kesme } \\
\text { kuvveti }(\mathrm{kN})\end{array}$} & \multicolumn{2}{|c|}{$\begin{array}{c}\text { Y yönünde meydana } \\
\text { gelen taban kesme } \\
\text { kuvveti (kN) }\end{array}$} \\
\hline & & & Payandasız & Payandalı & Payandasız & Payandalı \\
\hline G & Doğrusal Statik & & - & - & - & - \\
\hline EQx & $\begin{array}{l}\text { Doğrusal Davranış } \\
\text { Spektrumu }\end{array}$ & Max & 10554 & 10433 & 31 & 90 \\
\hline EQy & $\begin{array}{l}\text { Doğrusal Davranış } \\
\text { Spektrumu }\end{array}$ & Max & 31 & 90 & 9703 & 9739 \\
\hline
\end{tabular}


Tablo 3. (Devamı) Taban kesme kuvvetleri ve eksenel kuvvetler.

\begin{tabular}{|l|l|l|r|r|r|r|}
\hline G+EQx & Kombinasyon & Max & 10554 & 10433 & 31 & 90 \\
\hline G+EQx & Kombinasyon & Min & -10554 & -10433 & -31 & -90 \\
\hline G+EQy & Kombinasyon & Max & 31 & 90 & 9703 & 9739 \\
\hline G+EQy & Kombinasyon & Min & -31 & -90 & -9703 & -9739 \\
\hline
\end{tabular}

Dinamik analiz sonucunda yapının duvar ve tonoz elemanlarında hesaplanan gerilmelerden, her elemanın kendi yerel eksenine göre düşey doğrultuda meydana gelen çekme veya basınç gerilmeleri ile kayma gerilme dağılımları G+EQx ve G+EQy yük kombinasyonlarına göre ayrı ayrı hazırlanarak tüm yapı için Şekil 4'de verilmiştir. Yapıdaki en büyük gerilmeler her iki model için G+EQX yük kombinasyonunda ortaya çıkmıştır. Gerilme haritaları incelendiğinde, payandalı ve payandasız model için ortaya çıkan maksimum gerilmelerde önemli bir farkın oluşmadığı görülmektedir. Payandasız modelde en büyük normal gerilmenin $0,86 \mathrm{MPa}$ ile yapı temeline yakın noktada oluştuğu, payandalı modelde ise yine aynı bölgede $0,73 \mathrm{Mpa}$ olarak hesaplandığ 1 görülmüştür. Yapının daha rijit olan uzun doğrultusunda tanımlı G+EQy yük kombiansyonuna göre gerilme haritaları incelendiğinde, en büyük normal gerilmenin her iki model için 0,32 Mpa hesaplandığı görülmüştür.

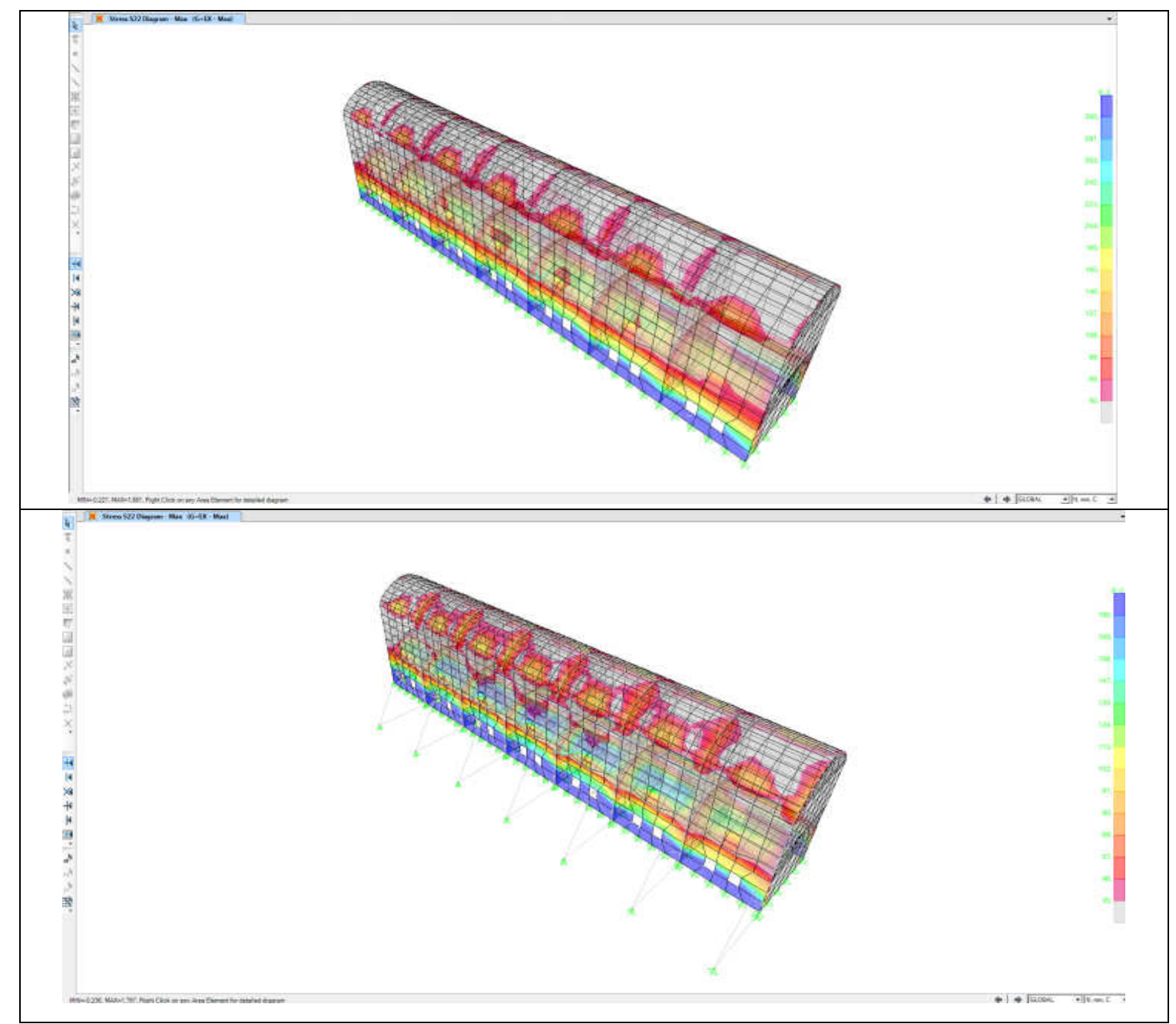

Şekil 4. G+EQX ve G+EQY yük kombinasyonları etkisinde her iki model için ortaya çıkan gerilme haritaları. 


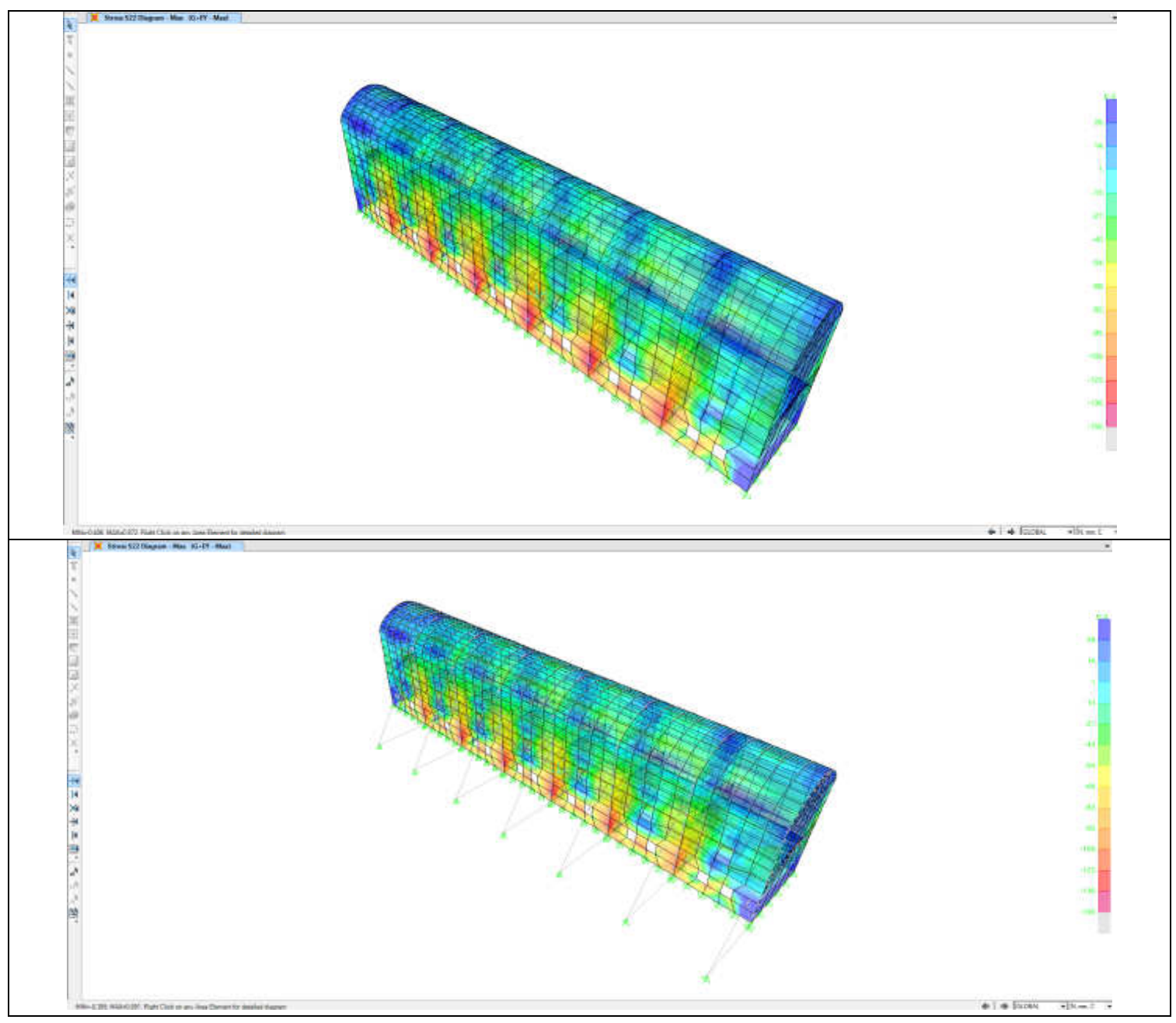

Şekil 4. (Devamı) G+EQX ve G+EQY yük kombinasyonları etkisinde her iki model için ortaya çıkan gerilme haritaları.

Tarihi yığma yapılar için önemli olan diğer parametre kayma gerilmesidir. $\mathrm{Bu}$ tür yapılarda kayma gerilmeleri, büyük kesitlerle karşılanmaya çalışılır. İncelenen modelde en büyük kayma gerilmelerinin kısa kenar doğrultusunda uygulanan yük kombinasyonu altında ara duvarlarda çıkması beklenir. Bu amaçla maksimum kayma gerilmesinin oluştuğu ara duvarlar her iki model için şekil 5'te verilmiştir. Her iki model için kayma gerilmesi değerleri payandasız ve payandalı model için sırasıyla 0,40 ve $0,35 \mathrm{MPa}$ olarak hesaplanmıştır.

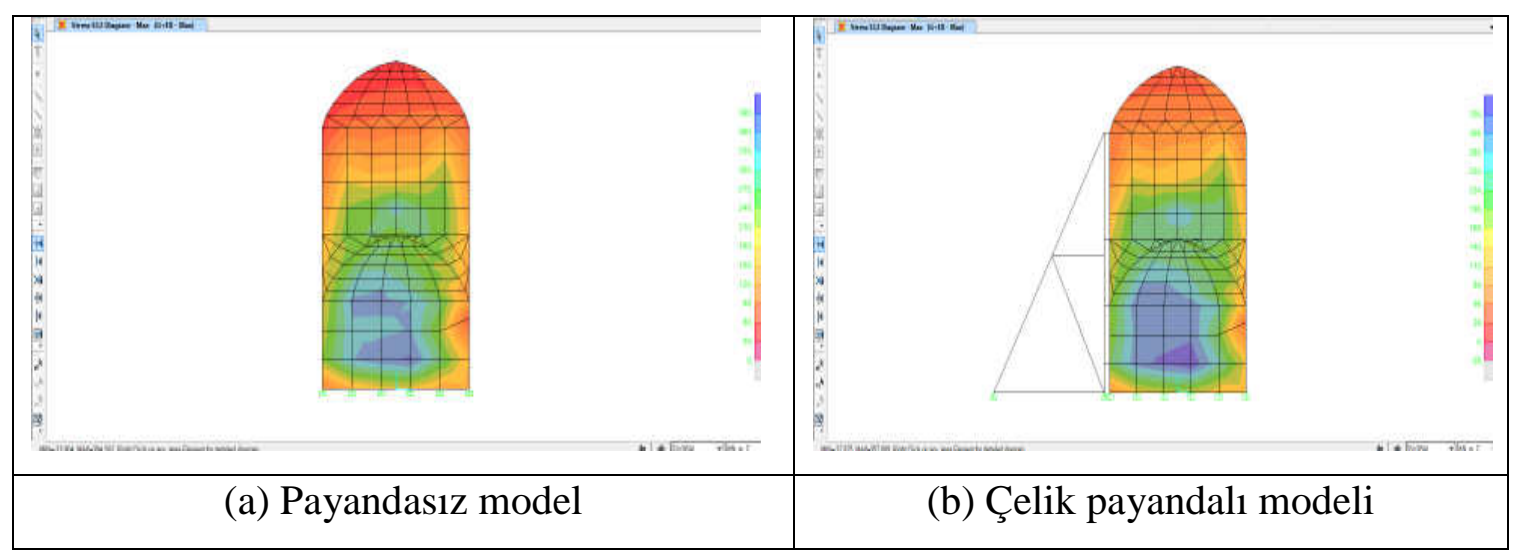

Şekil 5. Kayma gerilmeleri dağılımı. 
Şekil 6'da yapıyı oluşturan dört ana eleman için hesaplanan gerilmelerin payandalı ve payandasız model için değişimi karşılaştırmalı olarak verilmiştir. Şekil 6 dikkatli olarak incelendiğinde normal ve kayma gerilmelerinin her iki model için büyük ölçüde değişmediği görülebilir.

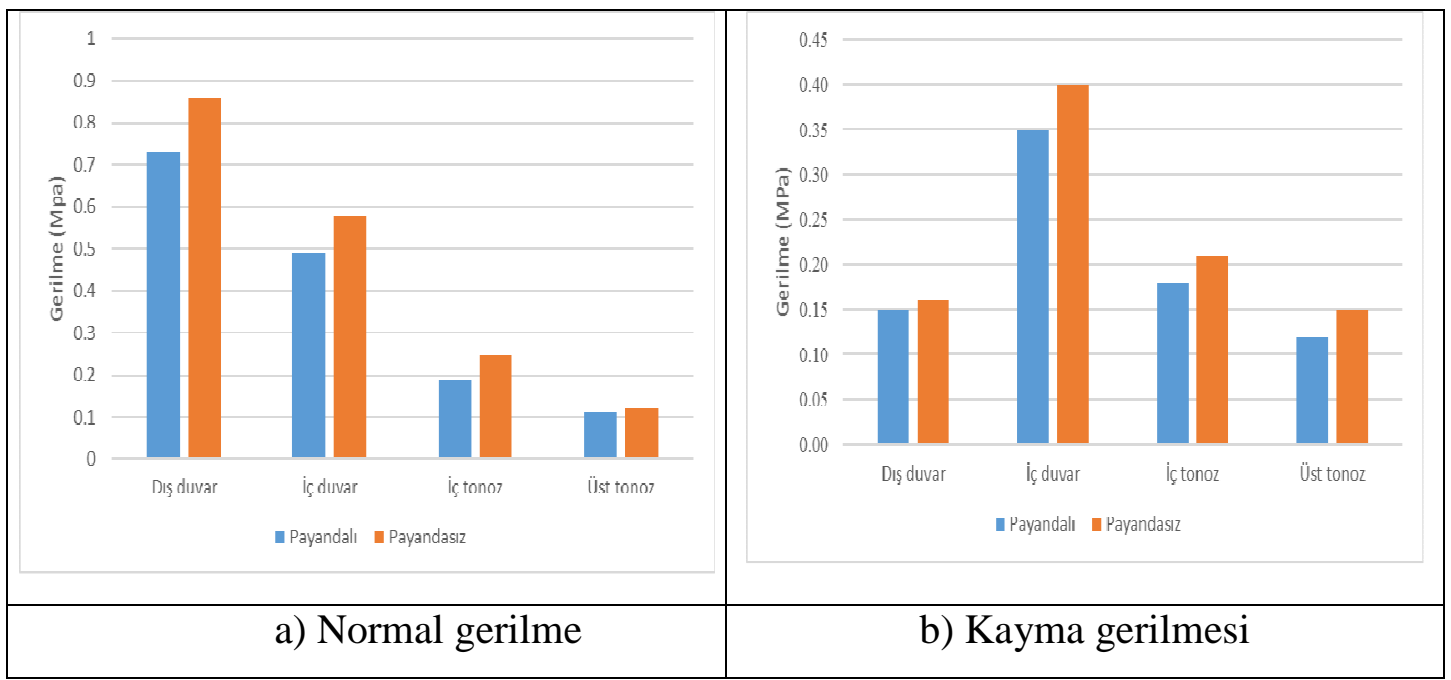

Şekil 6. Normal ve kayma gerilmelerindeki değișim.

Çelik payandaların tarihi yapıyla birleştiği uzun doğrultu duvarlarında oluşan kayma gerilmeleri şekil 7'de verilmiştir. Payandasız ve payandalı model için en büyük kayma gerilmesi uzun kenar doğrultusunda tanımlanmış yük kombinasyonunda ve duvar boşluklarına yakın noktalarda 0,28 MPa olarak hesaplanmıştır.

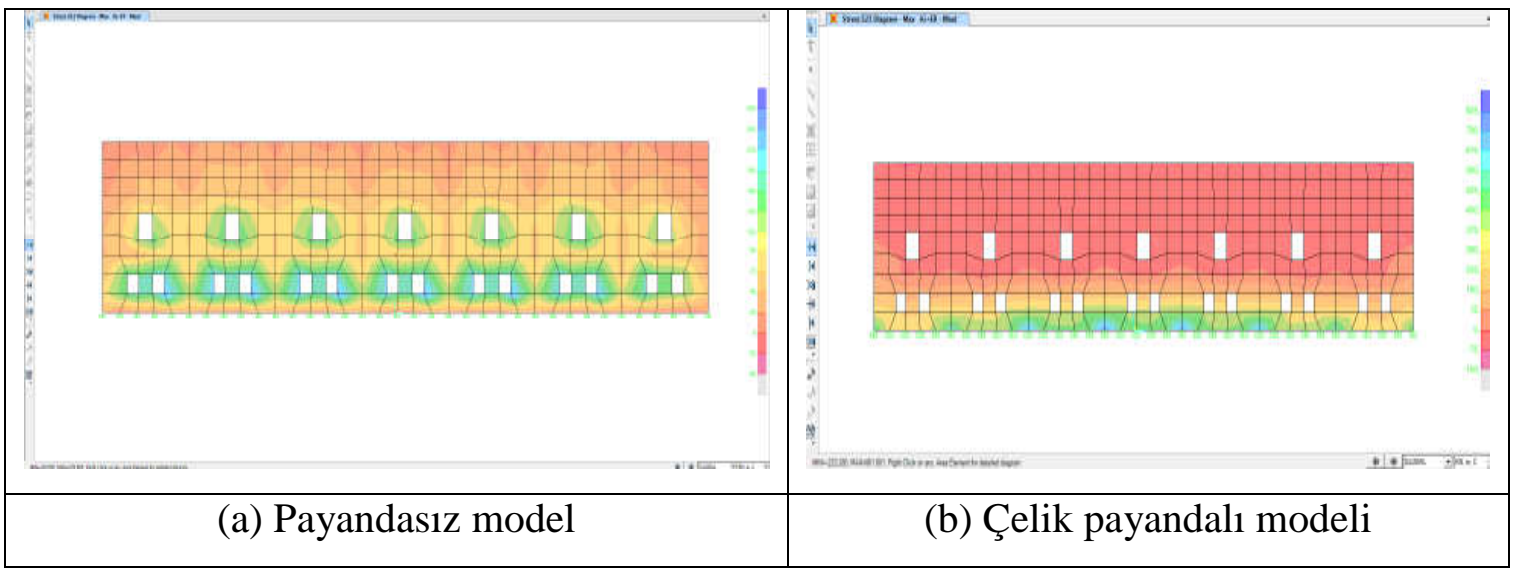

Şekil 7. G+EQy kombinasyonu için kayma gerilmesi dağılımı.

Yapıyı güçlendirme amacıyla yapılan çelik kafes payanda elemanlarında G+EQx yüklemesi için oluşan eksenel normal kuvvet, en çok zorlanan payanda için şekil 8' de verilmiştir. Kafes elemanlarından diş diyagonal çubuk en fazla zorlanan çubuktur. En fazla zorlanan bu çubuğun \%10 kapasite oranı ile çalıştı̆̆ yapısal analiz sonucunda tespit edilmiştir. 


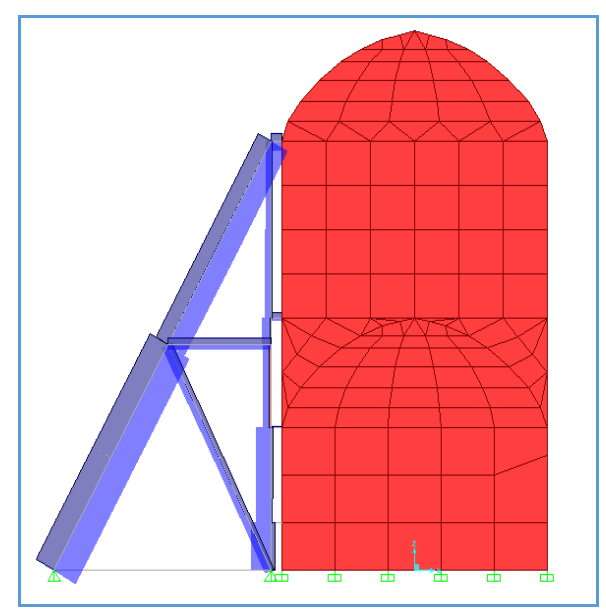

Şekil 8. Payanda çubuklarında oluşan eksenel kuvvetler.

\section{Sonuçlar ve tartışma}

Tarihi yapının ilgili kısmı çelik payandalı ve payandasız olarak modellenmiş ve analizi Türk deprem yönetmeliğinin Tokat için önerdiği deprem etkisine göre tanımlanan spektrum eğrisine göre yapılmıştır. Yapının sonlu elemanlar modelinde çelik ve kâgir bölümleri için doğrusal elastik malzeme özellikleri kullanılmıştır. Yapılan ayrıntılı hesaplar sonucunda her iki modelde dış duvar, iç duvar, tonozlar ve çelik payandadaki kuvvet, deformasyon ve gerilme etkileri detaylı olarak incelenmiştir. Buna göre;

- Analiz sonuçlarında payandasız ve payandalı model için ilk 5 mod karşılaştırılmıştır. Modal analiz sonuçlarına göre payandasız ve payandalı modelde ilk mod şekli için periyotlar sırasıyla $0,07718 \mathrm{~s}$ ve $0,07249 \mathrm{~s}$ olarak hesaplanmıştır. Tüm mod şekilleri için periyot değerleri incelendiğinde aradaki farkın ilk modda olduğu gibi çok küçük olduğu görülmüştür. Bu sonuçlara göre çelik payandaların yapı periyodunun azalması yönünde çok az bir etkisinin olduğu görülmüştür.

- Her iki modelde Kısa kenar yönündeki deprem yük kombinasyonu sonucunda en büyük ötelenme payandasız ve payandalı model için tonoz tepesinde sırasıyla $1,7 \mathrm{~mm}$ ve $1,5 \mathrm{~mm}$, uzun kenar yönünde ise her iki model için yine tonoz tepesinde 0,65 mm olarak gerçekleşmiştir. Hesaplanan ötelenmelerin bu kadar düşük kalmasında, $\mathrm{x}$ yönünde yeralan ikisi $125 \mathrm{~cm}$, diğerleri $80 \mathrm{~cm}$ kalınlığındaki 6 duvarın etkili olduğu düşünülmektedir. Payandanın tarihi yapının yanal deformasyon üzerinde kayda değer bir etkisinin olmadığı açıktır.

- Yapıdaki en büyük gerilmeler her iki model için G+EQx yük kombinasyonunda ortaya çıkmıştır. Payandasız ve payandalı modelde en büyük normal gerilme yapı temeline yakın noktada sırasıyla 0,86 ve 0,73 Mpa olarak hesaplanmıştır. Yapının daha rijit olan uzun doğrutusunda G+EQy yük kombiansyonuna göre en büyük normal gerileme, her iki model için 0,32 Mpa hesaplanmıştır. Her iki model için ortaya çıkan maksimum gerilmelerde önemli bir farkın oluşmadığı, bu açıdan bakıldığında da payandanın önemli bir etkisinin olmadığ görülmüştür. 
- Yapıdaki en büyük kayma gerilmeleri G+EQx ve G+EQy yük kombinasyonları için incelenmiştir. G+EQx yük kombinasonunda maksimum kayma gerilmeri ara duvarlarda payandasız ve payandalı model için sırasıyla 0,40 ve $0,35 \mathrm{MPa}$ olarak hesaplanmıştır. Bu değerler düşünüldüğünde payandanın, yapı üzerinde kısa doğrultuda kayma gerilmelerini azaltma açısından hemen hemen hiç etkisinin olmadığı söylenebilir. Uzun doğrultu için beklendiği gibi herhangi bir etkisi olmamıştır.

- Tarihi yapı ile çelik yapı arasındaki yük aktarımını sağlayan elemanlar modele ideal şartlarda alınmış olmasına rağmen çubuklar üzerine gelen eksenel normal kuvvetin çubuk kapasitesinin yaklaşık \%10 una karşılık geldiği görülmektedir. $\mathrm{Bu}$ sonuçlara göre çelik payanda ile kâgir yapı arasında etkilişimin çok sınırlı kaldığ1 görülmüştür.

- Yapı duvarında var olan geometrik süreksizlikler nedeni ile sayısal modelde ideal olarak tasarlanan bağlantı elemanlarının gerçekte bu şartlarda imal edilebilmesi mümkün değildir. Uygulamada, tarihi yap1 ile kafes payanda arasında yatay konumda yerleştirilmiş IPE profilinden narin bir çelik kirişin tarihi yapı ile destek yapısı arasındaki bağlantıyı sağlıklı bir şekilde gerçekleştirerek büyük kütlesel bir hareketi karşılayarak payandalara aktarabilmesi de ayrıca mümkün değildir.

Sonuç olarak uygulamanın bu halinin tarihi yapıyı olası bir deprem etkisinde hasardan korumasının beklenemeyeceği, ancak yapıda oluşacak büyük hasarlarda duvarların yıkılarak devrilmesini önlemeye bir katkı sağlayabileceği kanaatine varılmıştır. Ancak bu katkının daha fazla olabilmesi için payandaların duvar ortalarında konumlandırılmasının daha faydalı olacağı düşünülmektedir. Bu yüzden bu tür bir destek yapısının uygulanmadan önce mevcut yapı ile etkileşiminin çok iyi irdelenmesi ve gerekliliği yeterince tartışılması gerekmektedir. Ayrıca bu çalışmada ele alınan uygulamanın farklı tip strüktüre sahip tarihi yapılar için uygun olabileceği göz önünde bulundurulmalıdır.

\section{Kaynaklar}

[1] Bayraktar, A., Altunisik, A.C., Sevim, B. and Turker, T., Seismic response of a historical masonry minaret using a finite element model updated with operational modal testing, J. Vib. Control, 17(1), 129-149. (2010).

[2] Şengül G. Aydıngün, Tarih Boyunca Yaşanan Depremler Sonrası Ayasofya Onarımları, Deprem Sempozyumu, Kocaeli, (2005).

[3] Landolfo, R., Portioli, F., Mammana, O. and Mazzolani, F.M., Finite element and limit analysis of the large scale model of Mustafa Pasha Mosque in Skopje, strengthened with FRP, Proc. of the First Asia-Pacific Conference on FRP in Structures APFIS 2007, Hong Kong, 283-288, (2007).

[4] Bartolomeo Pantò, Linda Giresini Mauro Sassu and Ivo Caliò, Non-linear modeling of masonry churches through a disc macro-element approach, Earthquakes and Structures, 12(2), 223-236, (2017).

[5] Aksulu, B.I., Tokat Deveci Hanı, 9. Milletlerarası Türk Sanatları Kongresi, İstanbul, 1, 65-77, (1991). 
[6] https://www.flickr.com/photos/caner/23336053251/in/photolist-By8nBHbS8ZbM, (20.08.2017)

[7] Lourenco, P.B., Computations on historic masonry structures, Struct. Eng. Mater., 4(3), 301-319, (2002).

[8] Doğangün, A., Acar, R., Sezen, H., and Livaoğlu, R., Investigation of dynamic response of masonry minaret structures, Bulletin of Earthquake Engineering, 6, 505-517, (2008).

[9] Toker, S. and Unay, A.İ., Mathematical modeling and finite element analysis of masonry arch bridges, Gazi Univ. J. Sci., 17(2), 129-139, (2004).

[10] Seker, B.S., Cakir, F., Dogangun, A. and Uysal, H., Investigation of a masonry domed mosque by experimental tests and numerical analyses, Earthquakes and Structures, 6(4), 335-350, (2014).

[11] Aras, F., Krstevka, L., Altay, G., Tashkov, L., Experimental and numerical modal analyses of a historical masonary palace, Construction and Building Materials, 25, 81-91, (2011).

[12] Can, H., Joseph, K. and Unay, A.I., Seismic behaviour of historical masonry buildings with irregular geometry, J. Fac. Eng. Arch. Gazi Univ., 27(3), 679686, (2012).

[13] Betti, M., Vignoli, A., Modelline and Analysis of a Romanesque Church Under Earthquake loading: Assessment of Seismic Resistance, Engineering Structures, 1-16, (2007).

[14] Sap 2000, Integrated Structural Analysis and Desing Software, Computers and Structures, Inc., Ver. 15.1.0, Berkeley, California, (2012).

[15] Afet bölgelerinde yapılacak yapılar hakkında yönetmelik, Bayındırlık ve İskan Bakanlı̆̆ı, Ankara, (2007).

[16] Altunışık, A.C., Bayraktar, A. and Genç A.F., A study on seismic behaviour of masonry mosques after restoration, Earthquakes and Structures, 10(6), 13311346, (2016).

[17] Sayed Mohammad Motovali Emamia and Majid Mohammadi, Influence of vertical load on in-plane behavior of masonry infilled steel frames, Earthquakes and Structures, 11(4), 609-627, (2016). 